\title{
A systematic review on the accumulation of prophylactic dosages of low-molecular-weight heparins (LMWHs) in patients with renal insufficiency
}

\author{
Ferdows Atiq ${ }^{1}$ • Patricia M.L.A. van den Bemt ${ }^{1}$ - Frank W.G. Leebeek ${ }^{2}$. \\ Teun van Gelder ${ }^{1,3}$. Jorie Versmissen ${ }^{3}$
}

Received: 9 March 2015 / Accepted: 28 May 2015 / Published online: 14 June 2015

(C) The Author(s) 2015. This article is published with open access at Springerlink.com

\begin{abstract}
Purpose Although therapeutic dosages of most lowmolecular-weight heparins (LMWHs) are known to accumulate in patients with renal insufficiency, for the lower prophylactic dosages this has not been clearly proven. Nevertheless, dose reduction is often recommended. We conducted a systematic review to investigate whether prophylactic dosages of LMWH accumulate in renal insufficient patients.

Methods A comprehensive search was conducted on $17 \mathrm{Feb}-$ ruary 2015 using Embase, Medline, Web of Science, Scopus, Cochrane, PubMed publisher, and Google scholar. The syntax emphasized for LMWHs, impaired renal function, and pharmacokinetics. The search yielded 674 publications. After exclusion by reading the titles, abstracts, and if necessary the full paper, 11 publications remained.

Results For dalteparin and tinzaparin, no accumulation was observed. Enoxaparin, on the other hand, did lead to accumulation in patients with renal insufficiency, although not in patients undergoing renal replacement therapy. Bemiparin and certoparin also did show accumulation. No data were available for nadroparin.
\end{abstract}

Electronic supplementary material The online version of this article (doi:10.1007/s00228-015-1880-5) contains supplementary material, which is available to authorized users.

Jorie Versmissen

j.versmissen@erasmusmc.nl

1 Department of Hospital Pharmacy, Erasmus Medical Center, Rotterdam, The Netherlands

2 Department of Hematology, Erasmus Medical Center, Rotterdam, The Netherlands

3 Department of Internal Medicine, Erasmus Medical Center, PO Box 2040, 3000 CA Rotterdam, The Netherlands
Conclusions In this systematic review, we show that prophylactic dosages of tinzaparin and dalteparin are likely to be safe in patients with renal insufficiency and do not need dose reduction based on the absence of accumulation. However, prophylactic dosages of enoxaparin, bemiparin, and certoparin did show accumulation in patients with a creatinine clearance $(\mathrm{CrCl})$ below $30 \mathrm{ml} / \mathrm{min}$, and therefore, dose reduction is required. The differences in occurrence of accumulation seem to depend on the mean molecular weight of LMWHs.

Keywords Clinical trials $\cdot$ Heparins $\cdot$ Pharmacodynamics · Heparins $\cdot$ Venous thrombosis

\section{Introduction}

Low-molecular-weight heparins (LMWHs) are anticoagulants made by depolymerization of unfractioned heparin (UFH) [1, 2]. In the last decades, LMWHs have largely replaced UFH as anticoagulants, because they are at least equally effective in prevention and treatment of venous thromboembolisms (VTEs) and have many practical advantages, most importantly the possibility of subcutaneous administration without the need of routine laboratory monitoring of the anticoagulant response [3-8]. Moreover, LMWHs have a more predictable anticoagulant response, longer half-life (allowing once or twice daily administration), and a dose-independent elimination and they cause less heparin-induced thrombocytopenia $[1,2,9,10]$. There is conflicting evidence whether bleeding complications differ between LMWHs and UFH, although a Cochrane analysis showed that LMWHs reduce the occurrence of major bleedings [8, 11-14].

The molecular weights of the various LMWHs differ. Tinzaparin has the highest average molecular weight $(6500 \mathrm{Da})$, while certoparin has the lowest average molecular 
weight (3800 Da) [13]. Pharmacokinetics of different LMWHs vary: they differ in elimination half-life, clearance, and bioavailability $[15,16]$. This might be a consequence of the differences in molecular weight. Also with regard to pharmacodynamics, LMWHs vary: anti-Xa/anti-IIa activity ratios range between 1.5 and 2.5 (tinzaparin and certoparin) to 3.66.5 (reviparin) [13].

Since LMWHs are mainly excreted by the kidney, they may accumulate in patients with renal insufficiency increasing the risk of bleeding [17-19]. Due to above-described differences in pharmacokinetics, data on accumulation in renal insufficiency cannot be easily converted from one LMWH to another [2]. For instance, therapeutic dosages of different LMWHs do not all accumulate in patients with renal insufficiency: nadroparin and enoxaparin were found to accumulate, while tinzaparin did not [20-26]. For LMHWs that accumulate in a therapeutic dosage, dose reduction is often recommended. Also for the lower prophylactic dosages, such dose reductions have been suggested, especially for high prophylactic dosages such as those used in cancer patients or in highrisk surgery [24, 27-29].

Even in this era of novel oral anticoagulants, LMWHs will stay important for the initial treatment of VTE during the first 5-7 days in patients treated with dabigatran and edoxaban, as well as for prophylaxis of VTE. Especially for patients with severe renal insufficiency in which case the novel oral anticoagulants are contraindicated, it remains important to know whether LMWHs can be prescribed safely.

Therefore, we conducted a systematic review to investigate whether prophylactic dosages of various LMWHs lead to accumulation defined as an increase in anti-Xa activity and whether accumulation depends on molecular weight of the LMWH.

\section{Materials and methods}

The meta-analysis was prepared in accordance with the PRIS MA (Preferred Reporting Items for Systematic Reviews and Meta-Analyses) statement [30]. No prespecified formal protocol was registered.

\section{Article search}

A comprehensive, systematic literature search has been conducted on 17 February 2015 using Embase, Medline, Web of Science, Scopus, Cochrane, PubMed publisher, and Google scholar. The syntax emphasized for LMWHs, impaired renal function, and pharmacokinetics using synonyms and relevant terms. The search terms as used in Embase, as an example, are shown in a supplemental file. In addition to the search results, we manually searched reference lists of all relevant articles for additional studies.

\section{Inclusion criteria and exclusion criteria (eligibility criteria)}

We only included articles in English on prophylactic LMWH treatment, studying at least ten patients (non-pregnant and with no children) with renal impairment. We defined accumulation as an increase in anti-Xa activity after consecutive administration for several days. Therefore, we excluded studies which did not administer LMWH on consecutive days (except for studies in patients receiving renal replacement therapy) and did not measure anti-Xa activity on multiple days while giving LMWH. We excluded case reports, overviews, expert opinions, recommendations, reviews, and replies on articles. Abstracts of unpublished data were not excluded; authors were approached for additional information.

\section{Study selection and data collection}

A single reviewer excluded articles that did not meet the eligibility criteria by using the title and abstract. If necessary, the full text was read. If the reviewer could not decide whether to exclude the article, a second reviewer was asked for advice and both met to reach a consensus. Furthermore, a single reviewer collected relevant data from the included articles for the review.

\section{Risk of bias}

Risk of bias was evaluated at study level using the Cochrane Risk of Bias assessment tool. The criteria on random sequence generation, allocation, and blinding were disregarded.

\section{Results}

\section{Study selection}

The search yielded 1387 articles from which 713 were duplicates. Figure 1 shows a flow diagram illustrating literature evaluation.

\section{Characteristics}

Table 1 shows the study and patient characteristics. We included 11 articles of which one was on LMWH in continuous venovenous hemofiltration (CVVH) and one on hemodialysis patients. Five studies examined dalteparin accumulation, and five articles examined enoxaparin [31-37, 40, 41]. For tinzaparin, bemiparin, and certoparin, there was one study for each LMWH [35, 38, 39].

All studies were conducted prospectively. Two were randomized trials, and eight were cohort studies. Only one study did report clear prespecified primary outcomes. The number of 


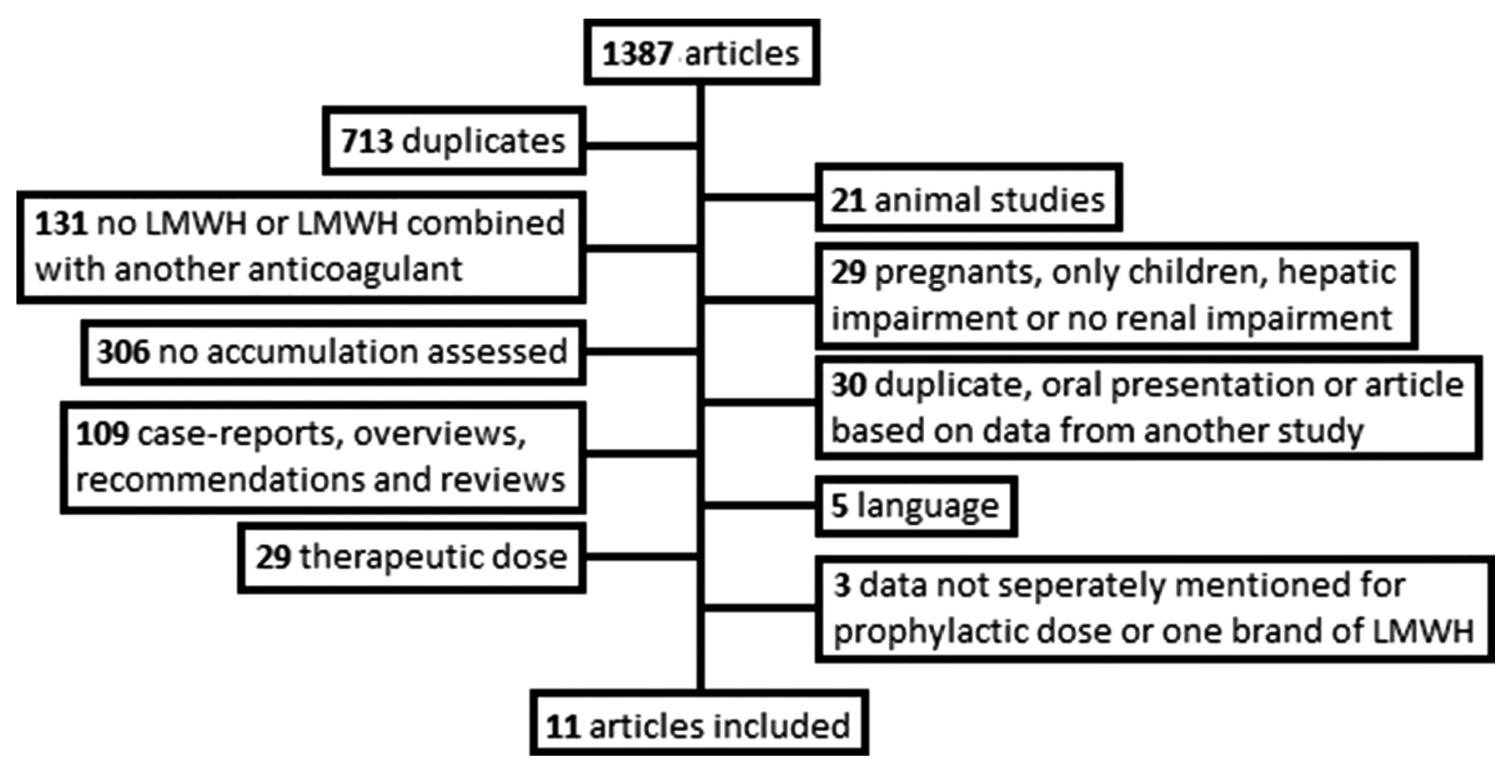

Fig. 1 Flow diagram illustrating literature evaluation

patients ranged between 12 and 138. Three studies only included patients on an intensive care unit (ICU), and three studies only included elderly patients (Table 1). The follow-up length per patient was 4 days to 3 weeks. Accumulation was mainly assessed by measuring peak anti-Xa activity or trough anti-Xa activity (Table 2). Six studies reported clinical outcomes like hemorrhagic events, thrombosis, and mortality rates.

\section{Dalteparin}

Dalteparin accumulation was studied in five articles. In patients on a general medical or surgical ward, no accumulation was found in a total of 157 patients by measuring peak anti-Xa activity on day 6 or day $10[32,34]$.

At the ICU, trough and peak anti-Xa activity did not show accumulation on day 9 or day 12 in a total of 157 patients not undergoing CVVH [31, 33].

Also in hemodialysis patients $(n=7)$ prescribed $2500 \mathrm{IU}$ dalteparin during hemodialysis sessions for 4 weeks, anti-Xa activity at different time points $(1,2,3,4,24$, and $28 \mathrm{~h}$ postinjection) were not significantly different between week 1 and week 4 [40]. The patients underwent hemodialysis sessions three times a week for $4 \mathrm{~h}$.

\section{Enoxaparin}

Three studies of which two in patients older than 75 years examined enoxaparin accumulation in, respectively, 125, 28, and 48 non-dialysis patients [35-37]. The studies in the elderly with $\mathrm{CrCl} 20-50 \mathrm{ml} / \mathrm{min}$ found a significantly higher maximum concentration $\left(C_{\max }\right)$, area under the curve (AUC), and trough anti-Xa activity ( $24 \mathrm{~h}$ postinjection) after 8 days administration and a higher peak anti-Xa activity after 10 days, compared to patients with better renal function [35, 36]. The other study in patients with different severity of renal insufficiency found accumulation (a significantly higher $C_{\max }$, longer half-life, higher AUC) already on day 4 in patients with $\mathrm{CrCl} \leq 30 \mathrm{ml} / \mathrm{min}$ [37].

Hemodialysis patients $(n=7)$ prescribed $40 \mathrm{mg}$ enoxaparin at hemodialysis sessions for 4 weeks, anti-Xa activity at different time points postinjection were not significantly different between week 1 and week 4 [40]. Also in ICU patients $(n=12)$ undergoing CVVH with a flow rate of $30 \mathrm{ml} / \mathrm{kg} / \mathrm{h}$, no accumulation of enoxaparin (30 mg daily) was found [41].

\section{Tinzaparin, bemiparin, and certoparin}

Administration of 4500 IU tinzaparin for 8 days in 27 patients older than 75 years with $\mathrm{CrCl} 20-50 \mathrm{ml} / \mathrm{min}$ and body weight below $65 \mathrm{~kg}$ did not lead to significant changes in $C_{\max }$, AUC, and trough anti-Xa activity ( $24 \mathrm{~h}$ postinjection) [35].

For 3500 IU bemiparin, $C_{\max }$ was higher and mean half-life was $2-4 \mathrm{~h}$ prolonged in patients with severe renal insufficiency after 4 days administration in 48 patients [38]. AUC significantly increased with the degree of renal insufficiency.

For $3000 \mathrm{IU}$ certoparin, $C_{\max }$ and AUC were significantly higher in patients with renal insufficiency compared to healthy controls after 5 days administration in 24 patients [39].

\section{Adverse events}

Six studies reported VTEs and bleeding events, although all were underpowered to find significant correlations [31-36]. In three of these studies, anti-Xa activity was 


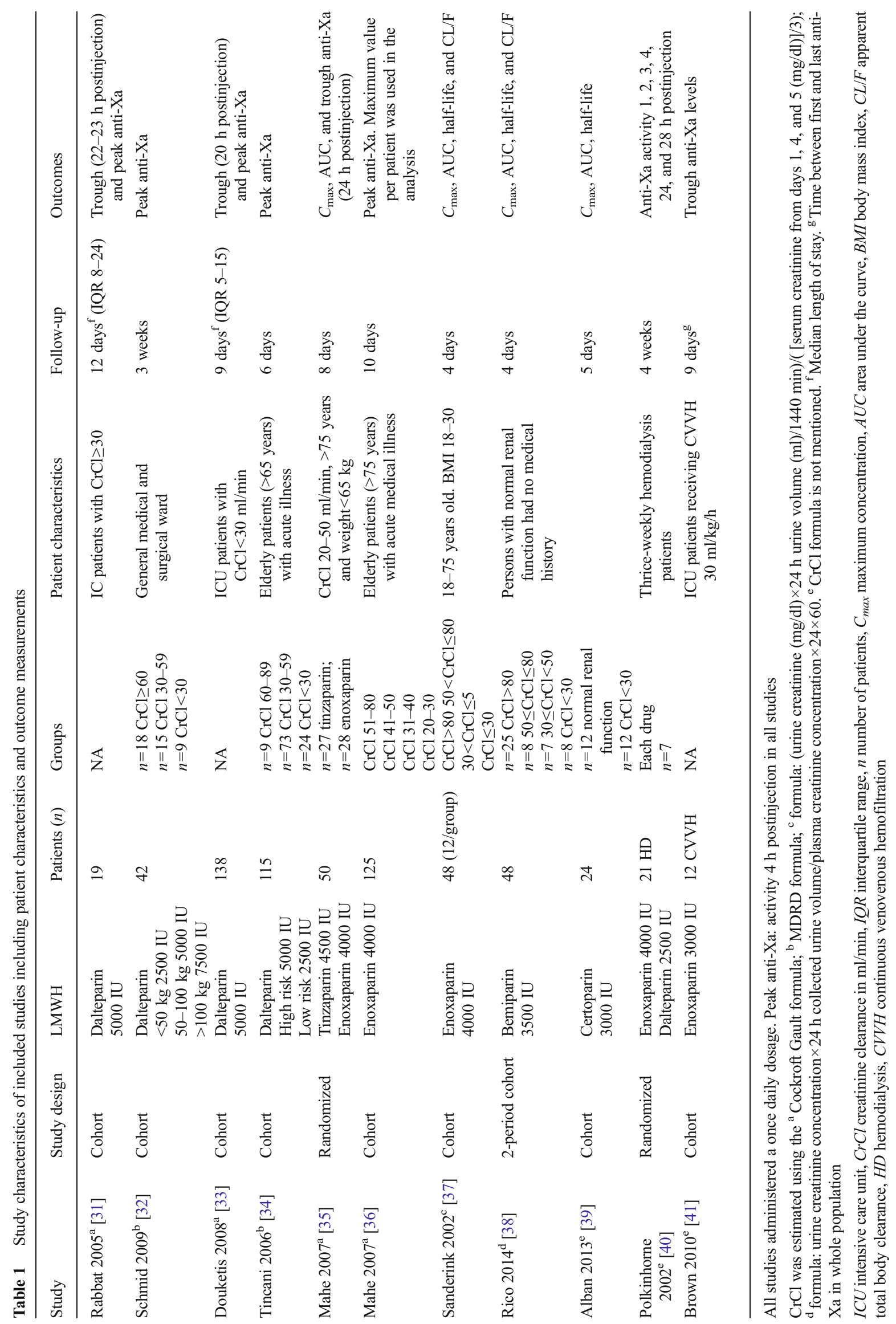


Table 2 Outcomes of included studies

\begin{tabular}{|c|c|c|c|c|c|c|c|}
\hline LMWH & Parameter & \multicolumn{6}{|l|}{ Results } \\
\hline \multirow[t]{3}{*}{ Dalteparin 5000 IU [31] } & Trough anti-Xa & \multicolumn{6}{|c|}{ Three patients value(s)> detection threshold; none above accumulation threshold } \\
\hline & Peak anti-Xa & \multicolumn{6}{|c|}{ Mean $0.30 \mathrm{U} / \mathrm{ml}(95 \%$ CI $0.27-0.33)$} \\
\hline & & \multicolumn{3}{|l|}{ Day 1} & \multicolumn{3}{|l|}{ Day 10} \\
\hline \multirow{2}{*}{$\begin{array}{l}\text { Dalteparin } 2500,5000, \\
\text { and } 7500 \mathrm{IU} \text { [32] }\end{array}$} & & $\mathrm{CrCl}>60$ & $\mathrm{CrCl} 30-59$ & $\mathrm{CrCl}<30$ & $\mathrm{CrCl}>60$ & $\mathrm{CrCl} 30-59$ & $\mathrm{CrCl}<30$ \\
\hline & $\begin{array}{l}\text { Peak anti-Xa } \\
\quad \text { (range) }\end{array}$ & $\begin{array}{l}0.28^{\mathrm{b}} \\
\quad(0.20-0.32)\end{array}$ & $\begin{array}{l}0.31^{\mathrm{b}} \\
\quad(0.23-0.46)\end{array}$ & $\begin{array}{l}0.28^{\mathrm{b}} \\
\quad(0.23-0.33)\end{array}$ & $\begin{array}{l}0.27^{\mathrm{a}, \mathrm{b}} \\
\quad(0.16-0.35)\end{array}$ & $\begin{array}{l}0.48^{\mathrm{a}, \mathrm{b}} \\
\quad(0.31-0.51)\end{array}$ & $\begin{array}{l}0.39^{\mathrm{a}, \mathrm{b}} \\
\quad(0.31-0.50)\end{array}$ \\
\hline \multirow[t]{3}{*}{ Dalteparin 5000 IU [33] } & Trough anti-Xa & \multicolumn{6}{|c|}{ Seven patients value(s)>detection threshold; none above accumulation threshold } \\
\hline & & \multicolumn{2}{|l|}{ Day 3} & \multicolumn{2}{|l|}{ Day 10} & \multicolumn{2}{|l|}{ Day 17} \\
\hline & $\begin{array}{l}\text { Peak anti-Xa } \\
\text { (range) }\end{array}$ & \multicolumn{2}{|c|}{$0.29(0.20-0.42)^{\mathrm{a}}$} & \multicolumn{2}{|c|}{$0.35(0.24-0.43)^{\mathrm{a}}$} & \multicolumn{2}{|c|}{$0.34(0.27-0.45)^{\mathrm{a}}$} \\
\hline \multirow{4}{*}{$\begin{array}{l}\text { Dalteparin } 2500 \text { and } \\
5000 \mathrm{IU} \text { [34] }\end{array}$} & & \multicolumn{6}{|l|}{ Day 6} \\
\hline & & \multicolumn{2}{|l|}{$\mathrm{CrCl}>60$} & \multicolumn{2}{|l|}{$\mathrm{CrCl} 30-59$} & \multicolumn{2}{|l|}{$\mathrm{CrCl}<30$} \\
\hline & $\begin{array}{l}\text { Peak anti-Xa } \\
\text { (range) }\end{array}$ & \multicolumn{2}{|l|}{$0.030(0.086)^{\mathrm{b}}$} & \multicolumn{2}{|l|}{$0.033(0.075)^{\mathrm{b}}$} & \multicolumn{2}{|l|}{$0.048(0.084)^{\mathrm{b}}$} \\
\hline & & \multicolumn{2}{|l|}{ Day 1} & \multicolumn{2}{|l|}{ Day 8} & \multicolumn{2}{|l|}{$p$ value } \\
\hline \multirow{4}{*}{$\begin{array}{l}\text { Enoxaparin } 4000 \text { IU } \\
\text { Tinzaparin } 4500 \text { IU [35] }\end{array}$} & & Enoxaparin & Tinzaparin & Enoxaparin & Tinzaparin & Enoxaparin & Tinzaparin \\
\hline & $C_{\max }$ & $0.55(0.14)$ & $0.44(0.16)$ & $0.67(0.23)$ & $0.46(0.19)$ & $<0.001$ & 0.296 \\
\hline & AUC & 354 (119) & $252(103)$ & $447(218)$ & $273(111)$ & $<0.001$ & 0.11 \\
\hline & Trough & $0.06(0.06)$ & $0.05(0.04)$ & $0.11(0.10)$ & $0.06(0.06)$ & 0.013 & 0.17 \\
\hline Enoxaparin 4000 IU [36] & & $\mathrm{CrCl} 51-80$ & $\mathrm{CrCl} 41-50$ & $\mathrm{CrCl} 31-40$ & $\mathrm{CrCl} 20-30$ & & \\
\hline & $\begin{array}{l}\text { Anti- } \mathrm{Xa} \mathrm{a}_{\max } 1-10 \\
p \text { value }\end{array}$ & $\begin{array}{l}0.60(0.16) \\
0.030^{\mathrm{c}}\end{array}$ & $\begin{array}{l}0.61(0.17) \\
0.039^{\mathrm{c}}\end{array}$ & $\begin{array}{l}0.61(0.24) \\
0.039^{\mathrm{c}}\end{array}$ & $\begin{array}{l}0.72(0.27) \\
\operatorname{Ref}\end{array}$ & & \\
\hline Enoxaparin 4000 IU [37] & & Severe RI & & & & & \\
\hline & $C_{\max }$ & $10-35 \%$ highe & & & & & \\
\hline & $\mathrm{AUC}_{(0-24)}$ & $65 \%$ higher $(\mathrm{d}$ & 4) & & & & \\
\hline & $\mathrm{CL} / \mathrm{F}$ & $27 \%$ (day 1$), 3$ & $9 \%$ (day 4 ) & & & & \\
\hline & $t_{1 / 2 \lambda z}$ & Increased with & he degree of RI & $p<0.012)$ & & & \\
\hline Bemiparin 3500 IU [38] & & Severe RI & & & & & \\
\hline & $C_{\max }$ & Higher & & & & & \\
\hline & $t_{1 / 2}$ & $2-4 \mathrm{~h}$ prolonge & & & & & \\
\hline & $\mathrm{CL} / \mathrm{F}$ & Lower & & & & & \\
\hline & AUC & Increased with & he degree of RI & & & & \\
\hline Certoparin 3000 IU [39] & & Severe RI & & & Ratio severe RI & normal renal fun & ction \\
\hline & $C_{\max }$ day 5 & 0.27 (range 0.1 & $-0.70)$ & & $1.39(95 \% \mathrm{CI}$ & $.04-1.85)$ & \\
\hline & $\mathrm{AUC}_{(0-24)}$ & 2.28 (range 1.3 & $-5.11)$ & & $1.52(95 \% \mathrm{CI}$ & $.07-2.17)$ & \\
\hline Enoxaparin $4000 \mathrm{IU}$ & & Week $1^{\mathrm{a}}$ & & & Week $4^{\mathrm{a}}$ & & \\
\hline Dalteparin 2500 IU [40] & & Dalteparin & Enoxaparin & & Dalteparin & Enoxaparin & \\
\hline & Anti-Xa (SEM) & $0.2(0.035)$ & $0.38(0.028)$ & & $0.26(0.038)$ & $0.40(0.055)$ & \\
\hline Enoxaparin 3000 IU [41] & Trough anti-Xa & Mean 0.11 (ran & ye $0.01-0.27, \mathrm{SD}$ & 0.07). None abo & e accumulation & areshold. & \\
\hline
\end{tabular}

All studies administered a once daily dosage. Peak anti-Xa: activity $4 \mathrm{~h}$ postinjection in all studies (all anti-Xa activity in IU/ml

$I Q R$ interquartile range, $\mathrm{CrCl}$ creatinine clearance in $\mathrm{ml} / \mathrm{min}, C_{\max }$ maximum concentration, $A U C$ area under the curve, $A$ nti- $X a_{\max } 1-10$ maximum anti$\mathrm{Xa}$ activity in 10 days, $A U C_{(0-24)}$ area under the $24 \mathrm{~h}$ plasma activity time curve, $C L / F$ apparent total body clearance, $R I$ renal insufficiency, $t_{1 / 2}$ elimination half-life, $t_{1 / 2 \lambda z}$ apparent terminal elimination half-life, $S E M$ standard error of the mean

${ }^{a}$ No significant changes between day 1 and day $x$

${ }^{\mathrm{b}}$ No significant changes between groups on day $x$

${ }^{\mathrm{c}}$ Compared to $\mathrm{CrCl} 20-30 \mathrm{ml} / \mathrm{min}$

undetectable during bleeding [31, 33, 34]. Five serious bleeding complications were reported when using enoxaparin, but anti-Xa activity in these patients was the same as in those without bleeding $(p=0.77)$ [36]. 
Table 3 Accumulation dependency on molecular weight

\begin{tabular}{|c|c|c|c|}
\hline LMWH & $\begin{array}{l}\text { Mean molecular } \\
\text { weight }(\mathrm{Da})[13,47]\end{array}$ & Accumulation therapeutic & Accumulation prophylactic \\
\hline Bemiparin & 3600 & $\mathrm{CrCl}<30 \mathrm{ml} / \mathrm{min}[38]$ & $\mathrm{CrCl}<30 \mathrm{ml} / \mathrm{min}[38]$ \\
\hline Certoparin & 3800 & $\mathrm{CrCl}<30 \mathrm{ml} / \mathrm{min}[48]$ & $\mathrm{CrCl}<30 \mathrm{ml} / \mathrm{min}[39]$ \\
\hline Nadroparin & 4300 & Yes $^{\mathrm{a}}[20]$ & No conclusion $^{\mathrm{b}}$ \\
\hline Enoxaparin & 4500 & $\mathrm{CrCl}<30 \mathrm{ml} / \mathrm{min}[21-24]$ & $\begin{array}{l}\mathrm{CrCl}<30 \mathrm{ml} / \mathrm{min} 4 \text { days [37] } \\
\text { and } 20-50 \mathrm{ml} / \mathrm{min} 8 \text { days [35] }\end{array}$ \\
\hline Dalteparin & 6000 & $\begin{array}{l}\mathrm{CrCl}<30 \mathrm{ml} / \mathrm{min} \text { after } 6 \text { days }[32] \\
\quad \text { but not after } 3[43]\end{array}$ & $\mathrm{No}^{\mathrm{c}}[31-34]$ \\
\hline Tinzaparin & 6500 & $\mathrm{No}^{\mathrm{d}}[25,26]$ & $\mathrm{No}^{\mathrm{d}}[35]$ \\
\hline
\end{tabular}

$\mathrm{CrCl}$ creatinine clearance

${ }^{\text {a }}$ Only correlation GFR/anti-Xa activity reported, no specific accumulation limit

${ }^{\mathrm{b}}$ Only one multiple dose study in six patients with $\mathrm{CrCl}$ above $30 \mathrm{ml} / \mathrm{min}$ and one single intravenous dose study $[45,46]$

${ }^{\mathrm{c}}$ Largest study no lower limit for $\mathrm{CrCl}^{33}$

${ }^{\mathrm{d}} \mathrm{CrCl}>20 \mathrm{ml} / \mathrm{min}$

\section{Discussion}

In this systematic review, we show that prophylactic dosages of dalteparin and tinzaparin did not accumulate in patients with renal insufficiency, while prophylactic dosages of enoxaparin, bemiparin, and certoparin did accumulate. Dalteparin also showed no accumulation in hemodialysis patients. Surprisingly, enoxaparin did not show accumulation in hemodialysis and CVVH patients, which might be due to removal by renal replacement therapy [42]. No data are available for nadroparin in patients with renal insufficiency.

These results are in accordance with studies on therapeutic dosages, except for dalteparin. Dalteparin is the only LMWH that appears to accumulate when used in a therapeutic dosage, while in studies using prophylactic dosages no accumulation was detected [31-34, 43]. A single-dose study showed reduced elimination of prophylactic dalteparin in patients with renal insufficiency, but apparently clearance is sufficient to prevent accumulation [31-34, 44].

Data on assessment of accumulation on prophylactic nadroparin in renal insufficiency are lacking. Only one multiple-dose study in six patients with $\mathrm{CrCl}$ above $30 \mathrm{ml} /$ min and one single-dose study were conducted $[45,46]$.

Our findings confirm the theory that accumulation seems to depend on the mean molecular weight of LMWHs as shown in Table 3. LMWHs with the lowest molecular weight (enoxaparin, bemiparin, certoparin, and nadroparin) all showed accumulation in a therapeutic dosage and a prophylactic dosage. Tinzaparin (the LMWH with the highest mean molecular weight) has shown not to accumulate in neither therapeutic nor prophylactic dosage. The most likely explanation for this counterintuitive relationship between size and accumulation is that the larger molecules are less dependent on renal clearance $[4,28,49,50]$.

In patients undergoing renal replacement therapy, it has been shown that many LMWHs are safe to use even in therapeutic dosages [28, 51]. For assessment of accumulation, only a few studies have been conducted. Most of these studies were excluded from this review as they included a single bolus administration, a therapeutic dosage, or no anti-Xa activity measuring at multiple days. Dalteparin showed accumulation in hemodialysis patients if prescribed in a therapeutic dosage, but not in a prophylactic dosage, whereas accumulation was found for prophylactic dosage in peritoneal dialysis patients $[19,40,52]$. Prophylactic dosages of enoxaparin and prophylactic and therapeutic dosages of nadroparin showed no accumulation in hemodialysis and CVVH patients [40, 41, 53, 54]. Tinzaparin accumulation has been found in a therapeutic dose in hemodialysis patients, but in a prophylactic dose, anti-Xa activity returned to baseline in $24 \mathrm{~h}[52,55]$. In conclusion, for dalteparin accumulation in renal replacement therapy is comparable to accumulation in patients without renal replacement therapy, but in other LMWHs accumulation in renal replacement therapy seems not to depend on mean molecular weight of LMWHs. The mechanism for accumulation in renal replacement therapy is unknown, but the highly negative charge of LMWHs might play a role [52]. More studies are needed to assess LMWH accumulation in patients on renal replacement therapy.

The strength of this review is first that we included only articles that objectively observed accumulation based on anti$\mathrm{Xa}$ activity rather than an accumulation prediction based on the half-life or the time it takes for anti-Xa activity to return to baseline. Second, by including the recent studies on bemiparin and certoparin, this paper confirms the earlier stated theory 
that accumulation depends on the mean molecular weight of LMWHs.

A limitation might be that we did not include singledose studies. However, a single-dose study is not suitable for objectively detecting accumulation [28, 32]. A significantly lower clearance or prolonged half-life for a LMWH in a single-dose study does not necessarily indicate that the LMWH accumulates, as is clear from the findings on dalteparin. Furthermore, follow-up of patients in some studies was relatively short (in some studies less than 1 week); however, if LMWHs would accumulate, this would be noticeable already after three dosages. Given the fact that patients tend to be discharged from the hospital within a few days, it is hardly possible to perform clinical studies with longer follow-up.

Another limitation might be that the risk of bias could not be assessed accurately. Considering bias across studies, we feel that a publication bias seems unlikely since both negative and positive outcomes in studies on accumulation have news value, and we included two abstracts of unpublished data. Furthermore, a possible confounder could be the difference in renal insufficiency onset (acute vs chronic) in different studies; however, there is no evidence that this can cause variance in anti-Xa activity.

A major limitation of all studies is that anti-Xa activity rather than hard clinical endpoints were studied. Although a study on hard clinical endpoints in patients with renal insufficiency is probably not feasible due to large numbers needed, it should be taken into account that the correlation between antiXa activity and occurrence of bleeding or VTE is not unambiguous [56-60]. The therapeutic and prophylactic target levels of anti-Xa activity are not supported by evidence of trials, but they are rather based on expert opinions [61, 62]. We also found in our review that in six studies that reported clinical outcomes, none of the patients with bleeding had higher anti-Xa activity than patients without bleeding [31-36]. However, the anti-Xa activity is considered to be the best test available to measure LMWH activity and to detect accumulation of LMWHs [4, 63].

In conclusion, for several LMWHs the guidelines that recommend dose reduction for prophylactic use in patients with renal insufficiency are evidence based, except for dalteparin, tinzaparin, and nadroparin. We recommend a dose reduction for prophylactic use of enoxaparin, bemiparin, and certoparin in patients with $\mathrm{CrCl}$ below $30 \mathrm{ml} / \mathrm{min}$ [24, 28, 29, 38, 39]. Prophylactic dosages of tinzaparin and dalteparin are likely to be safe in patients with renal insufficiency and do not need dose reduction. Studies are needed to assess accumulation of prophylactic dosages of nadroparin and for all LMWHs in patients undergoing renal replacement therapy.

Acknowledgments This work was funded by the Dutch Kidney Foundation (Safety of medication in renal insufficiency, MV 13.36)
Authors' Contributions F. Atiq contributed to the conception and design of the work, data acquisition and analysis, and writing of the manuscript. P.M.L.A. van den Bemt and F.W.G. Leebeek contributed to the conception and design of the work and revised the manuscript critically. T. van Gelder contributed to the conception and design of the work and data analysis and revised the manuscript critically. J. Versmissen contributed to the conception and design of the work, data acquisition and analysis, and writing and revising of the manuscript. All authors approved the final version of the manuscript.

Conflict of interest The authors declare that they have no competing interests.

Open Access This article is distributed under the terms of the Creative Commons Attribution 4.0 International License (http:// creativecommons.org/licenses/by/4.0/), which permits unrestricted use, distribution, and reproduction in any medium, provided you give appropriate credit to the original author(s) and the source, provide a link to the Creative Commons license, and indicate if changes were made.

\section{References}

1. Hirsh J, Levine MN (1992) Low molecular weight heparin. Blood 79(1):1-17

2. Hetzel GR, Sucker C (2005) The heparins: all a nephrologist should know. Nephrol Dial Transplant 20(10):2036-2042

3. Weitz JI (1997) Low-molecular-weight heparins. N Engl J Med 337(10):688-698

4. Hirsh J, Warkentin TE, Shaughnessy SG, Anand SS, Halperin JL, Raschke R, Granger C, Ohman EM, Dalen JE (2001) Heparin and low-molecular-weight heparin: mechanisms of action, pharmacokinetics, dosing, monitoring, efficacy, and safety. Chest 119(1 SUPPL):64S-94S

5. Attia J, Ray JG, Cook DJ, Douketis J, Ginsberg JS, Geerts WH (2001) Deep vein thrombosis and its prevention in critically ill adults. Arch Intern Med 161(10):1268-1279

6. Nurmohamed MT, Rosendaal FR, Buller HR, Dekker E, Hommes DW, Vandenbroucke JP, Briet E (1992) Low-molecular-weight heparin versus standard heparin in general and orthopaedic surgery: a meta-analysis. Lancet 340(8812):152-156

7. Gould MK, Dembitzer AD, Doyle RL, Hastie TJ, Garber AM (1999) Low-molecular-weight heparins compared with unfractionated heparin for treatment of acute deep venous thrombosis. A meta-analysis of randomized, controlled trials. Ann Intern Med 130(10):800-809

8. Geerts WH, Jay RM, Code KI, Chen E, Szalai JP, Saibil EA, Hamilton PA (1996) A comparison of low-dose heparin with lowmolecular-weight heparin as prophylaxis against venous thromboembolism after major trauma. N Engl J Med 335(10):701-707

9. Frydman A (1996) Low-molecular-weight heparins: an overview of their pharmacodynamics, pharmacokinetics and metabolism in humans. Haemostasis 26(Suppl 2):24-38

10. Warkentin TE, Levine MN, Hirsh J, Horsewood P, Roberts RS, Gent M, Kelton JG (1995) Heparin-induced thrombocytopenia in patients treated with low-molecular-weight heparin or unfractionated heparin. N Engl J Med 332(20):1330-1335

11. Thorevska N, Amoateng-Adjepong Y, Sabahi R, Schiopescu I, Salloum A, Muralidharan V, Manthous CA (2004) Anticoagulation in hospitalized patients with renal insufficiency: a comparison of bleeding rates with unfractionated heparin vs enoxaparin. Chest 125(3):856-863 
12. Davis R, Faulds D (1997) Nadroparin calcium. A review of its pharmacology and clinical use in the prevention and treatment of thromboembolic disorders. Drugs Aging 10(4):299-322

13. Boneu B (2000) Low molecular weight heparins: are they superior to unfractionated heparins to prevent and to treat deep vein thrombosis? Thromb Res 100(2):V113-V120

14. van Dongen CJ, van den Belt AG, Prins MH, Lensing AW (2004) Fixed dose subcutaneous low molecular weight heparins versus adjusted dose unfractionated heparin for venous thromboembolism. Cochrane Database Syst Rev 4, Cd001100. doi:10.1002/14651858. CD001100.pub2

15. Samama MM, Gerotziafas GT (2000) Comparative pharmacokinetics of LMWHs. Semin Thromb Hemost 26(Suppl 1):31-38

16. Collignon F, Frydman A, Caplain H, Ozoux ML, Le Roux Y, Bouthier J, Thebault JJ (1995) Comparison of the pharmacokinetic profiles of three low molecular mass heparins-dalteparin, enoxaparin and nadroparin-administered subcutaneously in healthy volunteers (doses for prevention of thromboembolism). Thromb Haemost 73(4):630-640

17. Boneu B, Caranobe C, Sie P (1990) Pharmacokinetics of heparin and low molecular weight heparin. Baillieres Clin Haematol 3(3): 531-544

18. Hirsh J, Raschke R (2004) Heparin and low-molecular-weight heparin: the seventh ACCP conference on antithrombotic and thrombolytic therapy. Chest 126(3 SUPPL):188S-203S

19. Schmid P, Brodmann D, Fischer AG, Wuillemin WA (2010) Prospective observational cohort study of bioaccumulation of dalteparin at a prophylactic dose in patients with peritoneal dialysis. J Thromb Haemost 8(4):850-852

20. Mismetti P, Laporte-Simitsidis S, Navarro C, Sie P, D'Azemar P, Necciari J, Duret JP, Gaud C, Decousus H, Boneu B (1998) Aging and venous thromboembolism influence the pharmacodynamics of the anti-factor Xa and anti-thrombin activities of a low molecular weight heparin (nadroparin). Thromb Haemost 79(6):1162-1165

21. Becker RC, Spencer FA, Gibson M, Rush JE, Sanderink G, Murphy SA, Ball SP, Antman EM, Investigators TA (2002) Influence of patient characteristics and renal function on factor Xa inhibition pharmacokinetics and pharmacodynamics after enoxaparin administration in non-ST-segment elevation acute coronary syndromes. Am Heart J 143(5):753-759

22. Bazinet A, Almanric K, Brunet C, Turcotte I, Martineau J, Caron S, Blais N, Lalonde L (2005) Dosage of enoxaparin among obese and renal impairment patients. Thromb Res 116(1):41-50

23. Chow SL, Zammit K, West K, Dannenhoffer M, Lopez-Candales A (2003) Correlation of antifactor Xa concentrations with renal function in patients on enoxaparin. J Clin Pharmacol 43(6):586-590

24. Lim W, Dentali F, Eikelboom JW, Crowther MA (2006) Meta-analysis: low-molecular-weight heparin and bleeding in patients with severe renal insufficiency. Ann Intern Med 144(9):673-684

25. Siguret V, Pautas E, Fevrier M, Wipff C, Durand-Gasselin B, Laurent M, Andruex JP, D’Urso M, Gaussem P (2000) Elderly patients treated with tinzaparin (innohep(registered trademark)) administered once daily (175 anti-Xa IU/kg): anti-Xa and anti-IIa activities over 10 days. Thromb Haemost 84(5):800-804

26. Pautas E, Gouin I, Bellot O, Andreux JP, Siguret V (2002) Safety profile of tinzaparin administered once daily at a standard curative dose in two hundred very elderly patients. Drug Saf 25(10):725733

27. Horlocker TT, Heit JA (1997) Low molecular weight heparin: biochemistry, pharmacology, perioperative prophylaxis regimens, and guidelines for regional anesthetic management. Anesth Analg 85(4):874-885

28. Schmid P, Fischer AG, Wuillemin WA (2009) Low-molecularweight heparin in patients with renal insufficiency. Swiss Med Wkly 139(31-32):438-452
29. Nutescu EA, Spinler SA, Wittkowsky A, Dager WE (2009) Lowmolecular-weight heparins in renal impairment and obesity: available evidence and clinical practice recommendations across medical and surgical settings. Ann Pharmacother 43(6):1064-1083

30. Moher D, Liberati A, Tetzlaff J, Altman DG, Group P (2009) Preferred reporting items for systematic reviews and meta-analyses: the PRISMA statement. PLoS Med 6(7), e1000097. doi:10.1371/ journal.pmed.1000097

31. Rabbat CG, Cook DJ, Crowther MA, McDonald E, Clarke F, Meade MO, Lee KA, Cook RJ (2005) Dalteparin thromboprophylaxis for critically ill medical-surgical patients with renal insufficiency. J Crit Care 20(4):357-363. doi:10.1016/j.jcrc. 2005.09.009

32. Schmid P, Brodmann D, Fischer AG, Wuillemin WA (2009) Study of bioaccumulation of dalteparin at a prophylactic dose in patients with various degrees of impaired renal function. J Thromb Haemost 7(4):552-558

33. Douketis J, Cook D, Meade M, Guyatt G, Geerts W, Skrobik Y, Albert M, Granton J, Hebert P, Pagliarello G, Marshall J, Fowler R, Freitag A, Rabbat C, Anderson D, Zytaruk N, Heels-Ansdell D, Crowther M (2008) Prophylaxis against deep vein thrombosis in critically ill patients with severe renal insufficiency with the lowmolecular-weight heparin dalteparin: an assessment of safety and pharmacodynamics: the DIRECT study. Arch Intern Med 168(16): 1805-1812

34. Tincani E, Mannucci C, Casolari B, Turrini F, Crowther MA, Prisco D, Cenci AM, Bondi M (2006) Safety of dalteparin for the prophylaxis of venous thromboembolism in elderly medical patients with renal insufficiency: a pilot study. Haematologica 91(7):976-979

35. Mahe I, Aghassarian M, Drouet L, Bal Dit-Sollier C, Lacut K, Heilmann JJ, Mottier D, Bergmann JF (2007) Tinzaparin and enoxaparin given at prophylactic dose for 8 days in medical elderly patients with impaired renal function. A comparative pharmacokinetic study. Thromb Haemost 97(4):581-586

36. Mahe I, Gouin-Thibault I, Drouet L, Simoneau G, Di Castillo H, Siguret V, Bergmann JF, Pautas E (2007) Elderly medical patients treated with prophylactic dosages of enoxaparin: influence of renal function on anti-Xa activity level. Drugs Aging 24(1):63-71

37. Sanderink GJCM, Guimart CG, Ozoux ML, Jariwala NU, Shukla UA, Boutouyrie BX (2002) Pharmacokinetics and pharmacodynamics of the prophylactic dose of enoxaparin once daily over 4 days in patients with renal impairment. Thromb Res 105(3): 225-231

38. Rico S, Antonijoan RM, Ballester MR, Gutierro I, Ayani I, Martinez-Gonzalez J, Borrell M, Fontcuberta J, Gich I (2014) Pharmacodynamics assessment of bemiparin after multiple prophylactic and single therapeutic doses in adult and elderly healthy volunteers and in subjects with varying degrees of renal impairment. Thromb Res 133(6):1029-1038

39. Alban S, Peterfai E, Melzer N, Hagedorn I, De Mey C (2013) Conventional prophylactic doses of certoparin do not cause exaggerated aXa-exposure in patients with severe renal insufficiency. Hamostaseologie 33(1):A65

40. Polkinghorne KR, McMahon LP, Becker GJ (2002) Pharmacokinetic studies of dalteparin (Fragmin), enoxaparin (Clexane), and danaparoid sodium (Orgaran) in stable chronic hemodialysis patients. Am J Kidney Dis 40(5):990-995

41. Brown LS, Bourne RS, Kitchen S, VanVeen J, Byrne S (2010) A service evaluation of venous thromboembolism prophylaxis with low molecular weight heparin (LMWH) in intensive care patients receiving continuous renal replacement therapy. Intensive Care Med 36:S293

42. Isla A, Gascon AR, Maynar J, Arzuaga A, Corral E, Martin A, Solinis MA, Munoz JL (2005) In vitro and in vivo evaluation of enoxaparin removal by continuous renal replacement therapies with 
acrylonitrile and polysulfone membranes. Clin Ther 27(9):14441451. doi:10.1016/j.clinthera.2005.09.008

43. Shprecher AR, Cheng-Lai A, Madsen EM, Cohen HW, Sinnett MJ, Wong ST, Billett HH (2005) Peak antifactor xa activity produced by dalteparin treatment in patients with renal impairment compared with controls. Pharmacotherapy 25(6):817-822

44. Stobe J, Siegemund A, Achenbach H, Preiss C, Preiss R (2006) Evaluation of the pharmacokinetics of dalteparin in patients with renal insufficiency. Int J Clin Pharmacol Ther 44(10):455-465

45. Goudable C, Saivin S, Houin G, Sie P, Boneu B, Tonthat H, Suc JM (1991) Pharmacokinetics of a low molecular weight heparin (Fraxiparine) in various stages of chronic renal failure. Nephron 59(4):543-545

46. Alhenc-Gelas M, Rossert J, Jacquot C, Aiach M (1995) Pharmacokinetic study of the low-molecular-weight heparin fraxiparin in patients with nephrotic syndrome. Nephron 71(2): $149-152$

47. Martinez-Gonzalez J, Vila L, Rodriguez C (2008) Bemiparin: second-generation, low-molecular-weight heparin for treatment and prophylaxis of venous thromboembolism. Expert Rev Cardiovasc Ther 6(6):793-802

48. Alban S, Peterfai E, Melzer N, Hagedorn I, De Mey C (2013) Conventional therapeutic doses of certoparin do not lead to exaggerated aXa-levels in all the patients with severe renal insufficiency. Hamostaseologie 33(1):A64

49. Laposata M, Green D, Van Cott EM, Barrowcliffe TW, Goodnight SH, Sosolik RC (1998) College of American Pathologists Conference XXXI on laboratory monitoring of anticoagulant therapy: the clinical use and laboratory monitoring of low-molecularweight heparin, danaparoid, hirudin and related compounds, and argatroban. Arch Pathol Lab Med 122(9):799-807

50. Davies RG, Rayment R (2010) Primum non nocere-NICE guidelines on venous thromboembolism. Anaesthesia 65(8):774-778

51. Lim W, Cook DJ, Crowther MA (2004) Safety and efficacy of low molecular weight heparins for hem dialysis in patients with endstage renal failure: a meta-analysis of randomized trials. J Am Soc Nephrol 15(12):3192-3206

52. Rodger MA, Ramsay T, MacKinnon M, Westphal M, Wells PS, McCormick B, Knoll G (2012) Tinzaparin versus dalteparin for periprocedure prophylaxis of thromboembolic events in hemodialysis patients: a randomized trial. Am J Kidney Dis 60(3):427-434

53. Hene IZ, Wiertz NR, Van Schilfgaarde M, Wester JPJ, Leyte A, Oudemans-Van Straaten HM (2009) Nadroparin anticoagulation in continuous venovenous hemofiltration (CVVH): kinetics and extracorporeal removal. Intensive Care Med 35:S44

54. Nurmohamed MT, ten Cate J, Stevens P, Hoek JA, Lins RL, ten Cate JW (1991) Long-term efficacy and safety of a low molecular weight heparin in chronic hemodialysis patients. A comparison with standard heparin. ASAIO Trans 37(3):M459-461

55. Hainer JW, Sherrard DJ, Swan SK, Barrett JS, Assaid CA, Fossler MJ, Cox DS, Williams RM, Pittenger AL, Stephenson CA, Hua TA (2002) Intravenous and subcutaneous weight-based dosing of the low molecular weight heparin tinzaparin (Innohep) in end-stage renal disease patients undergoing chronic hemodialysis. Am J Kidney Dis 40(3):531-538

56. Levine MN, Planes A, Hirsh J, Goodyear M, Vochelle N, Gent M (1989) The relationship between anti-factor Xa level and clinical outcome in patients receiving enoxaparine low molecular weight heparin to prevent deep vein thrombosis after hip replacement. Thromb Haemost 62(3):940-944

57. Leizorovicz A, Bara L, Samama MM, Haugh MC (1993) Factor Xa inhibition: correlation between the plasma levels of anti-Xa activity and occurrence of thrombosis and haemorrhage. Haemostasis 23(Suppl 1):89-98

58. Brophy DF, Martin EJ, Best AM, Gehr TW, Carr ME (2004) Antifactor Xa activity correlates to thrombin generation time, platelet contractile force and clot elastic modulus following ex vivo enoxaparin exposure in patients with and without renal dysfunction. J Thromb Haemost 2(8):1299-1304

59. Brophy DF, Martin EJ, Gehr TW, Carr ME Jr (2004) Enhanced anticoagulant activity of enoxaparin in patients with ESRD as measured by thrombin generation time. Am J Kidney Dis 44(2):270 277

60. Al Dieri R, Alban S, Beguin S, Hemker HC (2006) Fixed dosage of low-molecular-weight heparins causes large individual variation in coagulability, only partly correlated to body weight. J Thromb Haemost 4(1):83-89

61. Lim W (2010) Using low molecular weight heparin in special patient populations. J Thromb Thrombolysis 29(2):233-240

62. Boneu B, de Moerloose P (2001) How and when to monitor a patient treated with low molecular weight heparin. Semin Thromb Hemost 27(5):519-522

63. Smith BS, Gandhi PJ (2001) Pharmacokinetics and pharmacodynamics of low-molecular-weight heparins and glycoprotein IIb/IIIa receptor antagonists in renal failure. J Thromb Thrombolysis 11(1): $39-48$ 